University of Nebraska - Lincoln

DigitalCommons@University of Nebraska - Lincoln

6-26-2012

\title{
Assimilating MODIS and AMSR-E Snow Observations in a Snow Evolution Model
}

Steven J. Fletcher

Glen E. Liston

Christopher A. Hiemstra

Steven D. Miller

Follow this and additional works at: https://digitalcommons.unl.edu/usarmyceomaha

This Article is brought to you for free and open access by the U.S. Department of Defense at

DigitalCommons@University of Nebraska - Lincoln. It has been accepted for inclusion in US Army Corps of Engineers by an authorized administrator of DigitalCommons@University of Nebraska - Lincoln. 


\title{
Assimilating MODIS and AMSR-E Snow Observations in a Snow Evolution Model
}

\author{
STEVEn J. Fletcher AND GLEN E. Liston \\ Cooperative Institute for Research in the Atmosphere, Colorado State University, Fort Collins, Colorado \\ CHRISTOPHER A. HiEMSTRA \\ Cold Regions Research and Engineering Laboratory, U.S. Army Corps of Engineers, Fort Wainwright, Alaska \\ STEVEn D. MiLleR \\ Cooperative Institute for Research in the Atmosphere, Colorado State University, Fort Collins, Colorado
}

(Manuscript received 5 July 2011, in final form 26 June 2012)

\begin{abstract}
In this paper four simple computationally inexpensive, direct insertion data assimilation schemes are presented, and evaluated, to assimilate Moderate Resolution Imaging Spectroradiometer (MODIS) snow cover, which is a binary observation, and Advanced Microwave Scanning Radiometer for Earth Observing System (EOS) (AMSR-E) snow water equivalent (SWE) observations, which are at a coarser resolution than MODIS, into a numerical snow evolution model. The four schemes are 1) assimilate MODIS snow cover on its own with an arbitrary $0.01 \mathrm{~m}$ added to the model cells if there is a difference in snow cover; 2 ) iteratively change the model SWE values to match the AMSR-E equivalent value; 3) AMSR-E scheme with MODIS observations constraining which cells can be changed, when both sets of observations are available; and 4) MODIS-only scheme when the AMSR-E observations are not available, otherwise scheme 3. These schemes are used in the winter of 2006/07 over the southeast corner of Colorado and the tri-state area: Wyoming, Colorado, and Nebraska. It is shown that the inclusion of MODIS data enables the model in the north domain to have a $15 \%$ improvement in number of days with a less than $10 \%$ disagreement with the MODIS observation $24 \mathrm{~h}$ later and approximately $5 \%$ for the south domain. It is shown that the AMSR-E scheme has more of an impact in the south domain than the north domain. The assimilation results are also compared to station snow-depth data in both domains, where there is up-to-a-factor-of-5 underestimation of snow depth by the assimilation schemes compared with the station data but the snow evolution is fairly consistent.
\end{abstract}

\section{Introduction}

Snow plays an important part in geoscience modeling and forecasting issues. It is critical for meteorological modeling as a boundary condition, and as a water resource for meltwater runoff into river systems for urban and agricultural uses. The presence and distribution of snow is a key earth system variable affecting energy and water budgets as well as ecosystems.

When modeling snow evolution, it is important to have information from areas that are difficult to observe, or are sparsely populated, where weather stations are

Corresponding author address: Dr. Steven J. Fletcher, Cooperative Institute for Research in the Atmosphere, Colorado State University, 1375 Campus Delivery, Fort Collins, CO 80523-1375.

E-mail: fletcher@cira.colostate.edu not as abundant. There are models that approximate the processes involved in the evolution of snow, given different atmospheric forcings, types of snow, terrain, and vegetation properties. SnowModel is one such model that has been developed at Colorado State University (Liston and Elder 2006a) and is detailed in the next section. Owing to various limitations in initialization, source, and sink functions for adding/removing snow mass, and parameterization describing the evolution of snow, these models may not completely represent the observed deposition/melt properties of snow.

One way to constrain a model's analysis of snow parameters is through some form of data assimilation, which enables information from observations to modify the model's state vector for these parameters, but it should be noted that these observations come with errors of their own. However, the areas of interest may be 
inaccessible to traditional ground-based observations, and when available, only on irregular and coarse temporal intervals or where the ground-based measuring resources are limited. One way to overcome this is to introduce remote sensing data from satellites. The National Aeronautics and Space Administration (NASA) has a number of remote sensing devices that provide snow information. Commonly employed sensors include the two Moderate Resolution Imaging Spectroradiometers (MODIS) on the Aqua and Terra satellites and Advanced Microwave Scanning Radiometer for Earth Observing System (EOS) (AMSR-E) on the Aqua satellite.

One of the products available from MODIS is a snow cover mask. This product is at a resolution of $500 \mathrm{~m}$, which is useful in constraining snow evolution models like SnowModel that can run at high spatial and temporal resolution. However, snow cover is not a model variable but a binary function of the state variable: snow water equivalent (SWE). A problem with assimilating snow cover observations is that these are not a unique function of SWE. Any value of SWE that has an associated snow depth providing a measurable signal above the background vegetation will trigger a nonzero value in the MODIS snow cover mask. However, SnowModel can model snow under forest canopies (Liston and Elder 2006a) where satellites have known difficulties observing snow (Hall and Riggs 2007).

AMSR-E provides some information about SWE, but it is in the form of spatial averages over $25 \mathrm{~km} \times 25 \mathrm{~km}$ areas. This averaging gives rise to significant ambiguity due to the likely presence of snow heterogeneity at these scales. Another problem associated with AMSR-E for assimilation is its temporal coverage. There are often days during the year when the satellite provides partial or no coverage for the area of interest. There are also known errors associated with AMSR-E observations in forested areas (Foster et al. 2005; Clifford 2010). However, AMSR-E can observe through clouds while MODIS cannot.

There are many other factors besides vegetation affecting the accuracy of passive microwave SWE retrievals. As shown in Foster et al. (2005), the morphology of the snow changes retrieval accuracy as well as the brightness temperature calibration. Markus et al. (2006) investigate the impact of weather effects and snow evolution on the accuracy of snow-depth retrievals. Clifford (2010) provides a good summary of factors affecting accuracy of passive microwave SWE retrievals including snow morphology, presence of liquid water in the snowpack, soil properties, and land cover.

Data assimilation is becoming more common in snow applications, especially as it often results in improved snow estimates and model simulations. Data assimilation is used to create better snow-depth and SWE estimates from passive microwave data (Pulliainen 2006) and to enrich coarse-scale microwave data with higher-resolution visible datasets like MODIS (Liang et al. 2009; Goa et al. 2010; Durand et al. 2008). Model-centric approaches have been implemented to assimilate SWE ground and remotely sensed observations. Molotch and Margulis (2008) combined various sources of snow-covered area (SCA) [MODIS, Enhanced Thematic Mapper (ETM), and the Advanced Very High Resolution Radiometer (AVHRR)] with a snow depletion curve and snowmelt model to calculate SWE. Ensemble Kalman filters have been used to assimilate MODIS snow-covered fraction (Andreadis and Lettenmaier 2006) to update SWE estimates or SWE estimates from passive microwave sensors (De Lannoy et al. 2010) into land surface or hydrological models.

The ensemble Kalman filter has been used to assimilate MODIS snow cover fraction to enhance continentalscale snow water equivalent (Su et al. 2008). A form of optimal interpolation data assimilation is used with SnowModel in Liston and Hiemstra (2008), where the corrections that the scheme finds are applied retroactively to create improved fields prior to the assimilated observations. Kuchment et al. (2010) combined SCA, passive microwave SWE estimates, and interpolated ground measurements to initialize and perform snowpack model simulations yielding runoff estimates.

Data assimilation systems can be very computationally expensive to run and can require estimates of background errors covariances, ensemble member generation techniques, or being able to run an ensemble of numerical models. In this paper, four assimilation schemes are presented and tested that are based upon direct insertion techniques. This approach is computationally inexpensive and relatively quick but does assume that the observations are perfect, even though they are not. In this work snow cover observations are used to assess direct insertion techniques with MODIS and SnowModel. Direct insertion techniques have been used before to assimilate MODIS snow cover fraction observations to update SWE estimates (Rodell and Houser 2004; Zaitchik and Rodell 2009).

The four schemes just mentioned are based upon 1) using only MODIS observations and assigning an arbitrary correction to the model if the model's snow cover mask does not match MODIS's, or setting the model cell's SWE value to zero if needed; 2) an iterative scheme assimilating AMSR-E observations over the model equivalent area and adjusting the model's SWE value such that the average of the model equivalent area matches the AMSR-E observations; 3) a combined scheme wherein the MODIS snow cover data are assimilated first, followed by the assimilation of AMSR-E 
SWE data for spatially modified snow cover (applied when there is an AMSR-E image available on that day); and 4) a scheme that is similar to 3 but the Aqua MODIS data are assimilated on the days AMSR-E is not available and the Aqua MODIS/AMSR-E approach from 3 is followed when the dual observations are available.

The four schemes are compared to a run of SnowModel where no observations are assimilated over two different areas of Colorado during the winter 2006/07. During this period two large blizzards hit the high plains of eastern Colorado and the Front Range, depositing on average $0.6 \mathrm{~m}$ of snow that persisted for 2 months or more in some locations. The two areas of study have different topography and vegetation and as such pose interesting problems for the evolution of snow as well as for the detection of snow from the satellite's instruments.

The two locations that have been selected contain areas of sparse populations, limiting the number of ground-based observations; also, the snow cover persisted for over 60 days in areas where the vegetation in the domains should incur minimal error to the quality of the MODIS and AMSR-E observations. However, there appears to be problems in the latter part of the season relative to the melting snow signals. To evaluate the performance of the schemes with data that are independent of the satellite observations, snow-depth output from the assimilation schemes and the control run are compared to station snow-depth data in the domains.

Therefore, the remainder of the paper is set as follows: Section 2 is a brief overview of SnowModel, and section 3 is a summary of the MODIS and AMSR-E observations along with the pros and cons of both sets of observations relative to known errors associated with both sensors. In section 4 the details of the experiments, the model domains, and the assimilation approaches that were followed are summarized. In section 5 the results from the different assimilation experiments are presented. Section 6 comprises of conclusions and discussion of this work.

\section{SnowModel}

SnowModel (Liston and Elder 2006a; Liston et al. 2007; Liston and Mernild 2012) consists of four submodels that describe different physical processes in the prognostic evolution of snow parameters. The four submodels are MicroMet, EnBal, SnowPack, and SnowTran-3D. SnowModel is designed to run on spatial increments of 1-500 $\mathrm{m}$ and temporal resolution ranging from 10 min to 1 day. It can be applied using much larger grid increments (up to $10 \mathrm{~s}$ of $\mathrm{km}$ ) if the inherent loss in high-resolution (subgrid) information (Liston 2004) is acceptable. The processes that are represented in SnowModel are accumulation of snow from frozen precipitation, blowing snow redistribution and sublimation, interception, unloading and sublimation within forest canopies, snow density evolution, and snowpack ripening and melt. SnowModel includes the first order physics, which allow for the evolution of the snow with each of the global snow classes as defined in Sturm et al. (1995) and G. E. Liston and M. Sturm (2012, unpublished manuscript) — that is, ice, tundra, taiga, alpine/mountain prairie, maritime, and ephemeral.

\section{a. MicroMet}

MicroMet is a quasi-physically based, high-resolution, meteorological distribution model (Liston and Elder 2006b). This downscaling model is designed specifically to produce high-resolution meteorological forcing distributions required to run spatially distributed terrestrial models over a wide variety of landscapes. The outputs from MicroMet are air temperature, relative humidity, wind speed, wind direction, incoming solar radiation, incoming longwave radiation, surface pressure, and precipitation. All of these fields have different features that may or may not be easy to interpolate over different topography and vegetation. These atmospheric forcing fields were spatially interpolated to the 500-m SnowModel grid using standard MicroMet procedures for the experiments shown later.

\section{b. EnBal}

Enbal performs a surface energy balance calculation based upon the available model state information. This program simulates surface temperatures and energy and moisture fluxes in response to observed and/or modeled near-surface atmospheric conditions provided from MicroMet. The surface latent and sensible heat flux and snowmelt calculations are made using a surface energy balance model dependent on the solar radiation reaching Earth's surface, the surface albedo, the downwelling longwave radiation at the surface, the upward emitted longwave radiation from the surface, the turbulent exchange of latent heat, the conductive energy transport, and the residual energy available for melt. For snow and ice surfaces, SnowModel defines different surface albedos for the snow below forest canopies, the snow in forest-free areas, and for glacier ice.

\section{c. SnowPack}

SnowPack (Liston and Hall 1995) is a single-layer, snowpack evolution model that defines snowpack changes in response to the precipitation and melt fluxes defined by MicroMet. In this model the snowpack 
density changes with time in response to snow temperature and weight of overlying snow. There is also a second density modifying process that results from the snow melting. The melted snow decreases the snow depth and the associated meltwater is redistributed through the snowpack until a maximum snow density is reached. Any additional meltwater is assumed to reach the ground at the base of the snowpack. Static surface sublimation calculations are performed in EnBal to adjust the snowpack depth. Sublimation of blowing snow is calculated in SnowTran-3D, described below. The specific forcings used in this work are mentioned in section 4.

\section{d. SnowTran-3D}

SnowTran-3D (Liston and Sturm 1998; Liston et al. 2007) is a three-dimensional model that simulates snowdepth evolution resulting from wind-blown snow. The primary components of the SnowTran-3D model are 1) the wind-flow forcing fields, 2) the wind shear stress on the surface, 3) the transport of snow by saltation, 4) the transport of snow by turbulent suspension, 5) the sublimation of saltation and suspended snow, and 6) the accumulation and erosion of snow at the snow surface.

There are 23 predefined vegetation types and 7 userdefined types that are used in SnowModel. The 23 predefined types are shown in Table 1 along with their associated snow-holding depths, which describe the minimum depths that the snow must be in the grid cell of a given vegetation classification such that the snow above this depth is available for wind transport. It should be noted that SnowTran-3D is not used in the experiments shown because of the 500-m resolution used, but this is to highlight that it is available.

\section{Snow observation sensors and products}

\section{a. MODIS snow cover product}

MODIS uses a cross-track scan mirror to image Earth and its atmosphere. MODIS features 36 discrete, narrow spectral bands in the optical portion of the electromagnetic spectrum, from approximately $0.4 \mu$ to $14.0 \mu \mathrm{m}$ (Hall and Riggs 2007). MODIS flies on both the Aqua and Terra satellites. The Terra orbit, for example, has a local equatorial crossing at approximately 1030 LT on its descending node, while the Aqua satellite has a local equatorial crossing time at approximately $1330 \mathrm{LT}$ on its ascending node. For this work the data from the Aqua's MODIS sensor are used since the AMSR-E sensor is only present on the Aqua satellite. The simultaneous observations allow for the evaluation of assimilation methods 3 and 4 described in section 4 .
TABLE 1 . The 23 predefined vegetation types and the associated snow-holding depth for use in SnowModel.

\begin{tabular}{rllc}
\hline \hline & Class & \multicolumn{1}{c}{ Description } & $\begin{array}{r}\text { Snow-holding } \\
\text { depth }(\mathrm{m})\end{array}$ \\
\hline 1 & Forest & Coniferous forest & 15.00 \\
2 & Forest & Deciduous forest & 12.00 \\
3 & Forest & Mixed forest & 14.00 \\
4 & Forest & Scattered short conifer & 8.00 \\
5 & Forest & Clearcut conifer & 4.00 \\
6 & Shrub & Mesic upland shrub & 0.50 \\
7 & Shrub & Xeric upland shrub & 0.25 \\
8 & Shrub & Playa shrubland & 1.00 \\
9 & Shrub & Shrub wetland/riparian & 1.75 \\
10 & Shrub & Erect shrub tundra & 0.65 \\
11 & Shrub & Low shrub tundra & 0.30 \\
12 & Grass & Grassland rangeland & 0.15 \\
13 & Grass & Subalpine meadow & 0.25 \\
14 & Grass & Tundra (nontussock) & 0.15 \\
15 & Grass & Tundra (tussock) & 0.20 \\
16 & Grass & Prostrate shrub tundra & 0.10 \\
17 & Grass & Arctic gram, wetland & 0.20 \\
18 & Bare & Bare & 0.01 \\
19 & Water & Water/possibly frozen & 0.01 \\
20 & Water & Permanent snow/glacier & 0.01 \\
21 & Human & Residential/urban & 0.01 \\
22 & Human & Tall crops & 0.40 \\
23 & Human & Short crops & 0.25 \\
\hline
\end{tabular}

MODIS snow and sea ice products are distributed through the National Snow and Ice Data Center in Boulder, Colorado. The MODIS product used in the experiments shown in section 5 is daily snow cover product, MYD10A1, which is provided at a 500-m resolution. The standard snow cover product is based upon the normalized difference snow index (Hall and Riggs 2007).

\section{b. AMSR-E snow water equivalence}

The AMSR-E sensor is a 12-channel, six-frequency, passive microwave radiometer system that measures microwave brightness temperature from radiation released from the underlying surface, the snowpack, and the atmosphere. The snow crystals in the snowpack scatter microwave radiation, where deeper snowpacks have more snow crystals available to scatter microwave energy. Hence the microwave brightness temperatures are lower than for shallow snowpacks, where there are fewer snow crystals to scatter the microwave radiation. In general, observed microwave brightness temperatures are a function of snow grain size, stratigraphy, density, physical temperature, liquid water content, as well as soil properties, vegetation, and atmospheric properties (Kelly 2009).

The baseline AMSR-E SWE retrieval algorithm is based upon methods that are described in Chang et al. 
(1987) and Chang et al. (1997). A snow-depth retrieval is applied to each snow-detected brightness temperature pixel and projected into a $25 \mathrm{~km} \times 25 \mathrm{~km}$ EASE grid cell. The number of instantaneous field-of-view retrievals comprising the accumulated snow-depth total is used to convert the total from all daily descending granules into an average snow depth. This snow depth is then converted to SWE through some preassigned snow density climatology.

\section{c. Pros and cons of both sensors}

Two strengths of the MODIS data are 1) its 500-m spatial resolution, which then provides high-resolution snow cover data for a snow evolution model, and 2) the temporal resolution with snow cover information being available twice a day (when not obscured by clouds). In addition, fractional snow cover observations also produced by MODIS are strongly related to SWE and the melt rates that snowpacks have experienced in the past, and these relationships have been used with considerable success in previous snow distribution studies (e.g., Cline et al. 1998; Liston 1999; Molotch 2009). On the downside, snow cover has a nonunique correspondence with SWE.

A strength of the AMSR-E observations is that the retrieved SWE corresponds directly to a model variable, allowing for direct comparisons between the two. Another strength is that the AMSR-E sensor is not affected by clouds in the same way as the MODIS sensor. However, the spatial resolution of AMSR-E SWE observations is coarse at $25 \mathrm{~km}$, compared to SnowModel's resolution, and introduces another form of nonuniqueness. There are 2500 model cells nested inside each of the AMSR-E observation and each of these cells can contribute toward the model equivalent average of the AMSR-E observation. If there are no constraints for the location of the changes in SWE then each cell is treated equally. This can be mitigated to some extent by introducting the MODIS snow cover as an a priori constraint to this SWE distribution, but even here the problem of reconciling model-averaged and AMSR-E SWE remains a grossly ill-posed problem. It should also be noted that there are errors associated with the AMSR-E SWE and MODIS snow cover retrievals related to vegetation, snow morphology, and meteorological factors.

Another problem with the AMSR-E observations is the resolution of the temporal sampling. Unlike MODIS, AMSR-E observations are not available every day because of the smaller swath width of AMSR-E and its availability on the Aqua satellite. There are at most 3-4 consecutive days when complete AMSR-E observations over the domains of interest for our experiments are available, followed by observation gaps. It should be noted as well that several days can occur between available MODIS images, when cloud cover persists, especially in winter and early spring months.

\section{Experimental design}

The aim of this section is to present the different configurations of SnowModel along with the combinations of the satellite data used in the assimilation algorithms. The geographic location and topographical and vegetation features of the two domains that are used for the experiments are described in sections $4 \mathrm{~b}$ and $4 \mathrm{a}$. The configuration for SnowModel are described in section 4c. Finally, in sections $4 \mathrm{~d}-\mathrm{g}$ the observation operators for MODIS snow cover and AMSR-E SWE are described, along with the assimilation algorithms to use these operators.

During December of 2006, two storms occurred, often referred to as "four corners" storms, since the centers of the low-pressure system were over the four corners of Colorado, Utah, New Mexico, and Arizona. The positions of these two lows enabled a counterclockwise flow that advected moisture from the Gulf of Mexico toward the Rocky Mountains, creating an upslope motion resulting in heavy snowfall along the front range of Colorado. The two storms occurred within 10 days of each other. The first of the two storms resulted in large amounts of snow being deposited along the Front Range, the mountains, and the eastern plains of Colorado. The second storm took a more southerly route than the first, slowing down as it headed northeastward across the ColoradoKansas border. As such this second storm deposited large amounts of snow near the Colorado-Kansas border in a large mostly rural area and contrary to the topographical gradient. Therefore, the time period for the experiments performed for this work is the winter season of 2006/07.

\section{a. North domain}

The first domain, referred to hereafter as the north domain, is bounded by the latitudes and longitudes $40^{\circ}-$ $42^{\circ} \mathrm{N}, 105^{\circ}-103^{\circ} \mathrm{W}$. Inside the north domain are the cities of Greeley, Colorado; Cheyenne, Wyoming; and Scottsbluff, Nebraska. Topographically the north domain has some challenges, with part of the Laramie Mountains in the west; the Cheyenne Ridge in the center, which is nearly contained by the field of view of a single AMSR-E pixel; and the South Platte River cutting across from the east. The topographical contour plot for this domain is shown in Fig. 1a.

The north domain is covered by a majority of grasslands and croplands (Fig. 1a). However, there is also wheat stubble, along with reservoirs near Greeley and the South Platte River and its tributaries. 


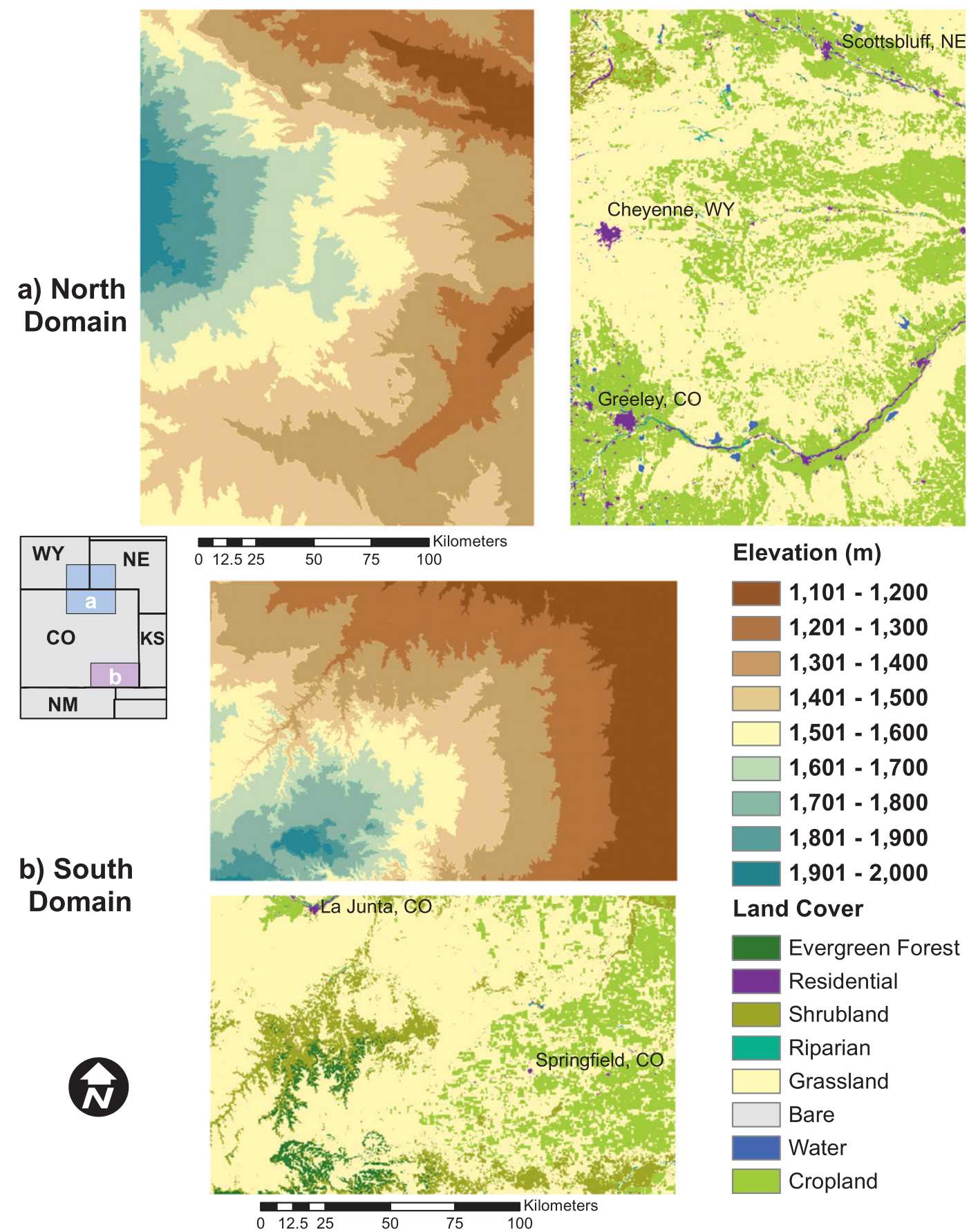

FIG. 1. Topographical and vegetation plots: (a) north domain and (b) south domain, where north is represented by increasing along the $y$ axes.

\section{b. South domain}

The second experimental area, referred to hereafter as the south domain, covers the southeastern corner of Colorado with latitude-longitude boundaries $37^{\circ}-38^{\circ} \mathrm{N}$, $104^{\circ}-102^{\circ} \mathrm{W}$. The topographical plot of the south domain is shown in Fig. 1b. A clear feature in this domain is the Purgatory River and the Picketwire Canyon in the western half. This canyon is approximately $100 \mathrm{~m}$ lower than the surrounding terrain. Also present in the domain are the two small cities, Springfield and La Junta, Colorado. There are also two small mountains 
TABLE 2. Percentage of each vegetation class for both the north and south domains.

\begin{tabular}{lcc}
\hline \hline Vegetation class $\%$ & North domain & South domain \\
\hline Forest & $0.31 \%$ & $3.4 \%$ \\
Shrub & $2.65 \%$ & $13.98 \%$ \\
Grass & $62.53 \%$ & $65.27 \%$ \\
Bare & $0.85 \%$ & $0.23 \%$ \\
Water & $1.72 \%$ & $0.4 \%$ \\
Human residential & $1.21 \%$ & $0.28 \%$ \\
Human crops & $30.71 \%$ & $16.45 \%$ \\
\hline
\end{tabular}

in the southern part of the domain that rise about $350 \mathrm{~m}$ above the surrounding terrain. The elevation of the domain decreases from west to east and from south to north. The highest point is approximately $2100 \mathrm{~m}$ while the lowest point is approximately $1000 \mathrm{~m}$. Predominant land covers include grassland, cropland, and shrubland (second plot in Fig. 1b).

The southern domain was selected in part because the two storms during the winter of $2006 / 07$, mentioned above, deposited large amounts of snow here. As such, there was significant snow cover for a considerable time where MODIS was able to observe the evolution of the snow with effectively minimum interference from vegetation, as only a small part of this domain is covered in tree canopies. For a summary of both domains' vegetation class and land use coverage percentages, refer to Table 2.

Given the previous work on the errors associated with MODIS and AMSR-E and their snow products and observations, the errors associated with respect to vegetation should be small but not zero, so they will affect the direct insertion techniques that are used. However, there are still errors associated with snow morphology, liquid water present in the snow, or soils that can affect the accuracy of the observations.

\section{c. Snow Model configurations}

SnowModel is configured to have a $500-\mathrm{m}$ horizontal resolution for the domains described in sections $4 \mathrm{a}$ and $4 \mathrm{~b}$, which results in 152427 grid cells in the north domain and 82340 in the south domain. The temporal time step is $1 \mathrm{~h}$, with the model SWE fields outputted every $6 \mathrm{~h}$. The model uses the Universal Transverse Mercator (UTM) projection, where this projection partitions the globe into 60 zones along the equator into transverse projections. The two domains used in this paper are in zone 13. All of the observations are projected into the UTM projection to be assimilated directly into the model. The atmospheric external forcings come from the North American Land Data Assimilation System version 2 forcings (Mitchell et al. 2004), which are air temperature, relative humidity, wind speed, wind direction,

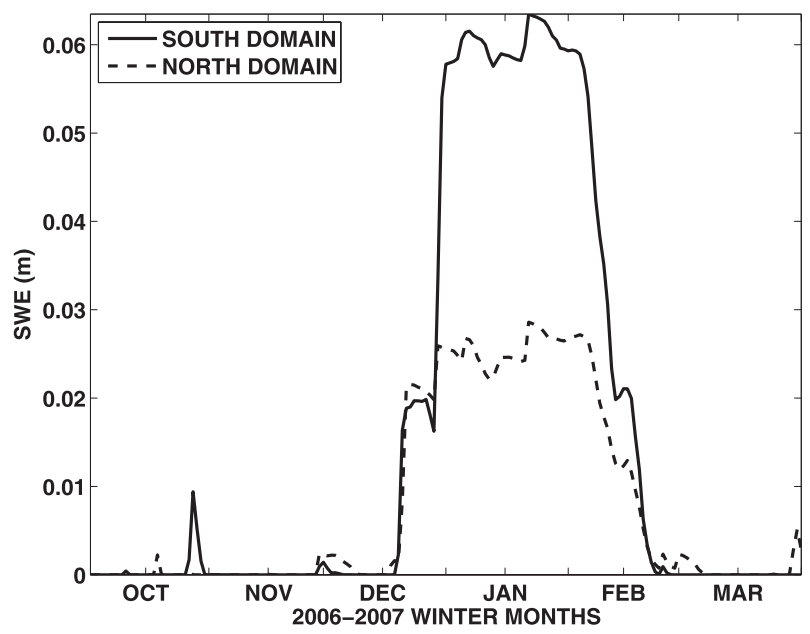

FIG. 2. Spatial average model SWE (m) for the north and south domains for the 2006/07 winter season.

and precipitation, and available hourly on a $1 / 8^{\circ}$ grid covering the United States. These atmospheric forcings are interpolated in the MicroMet program allowing for variation according to topography and land cover.

Topographical data is derived from the 30-m United States Geological Survey National Elevation Dataset (2008) covering the study area. These data are resampled to $500 \mathrm{~m}$ (cubic interpolation) and matched with the land cover. Land cover data used in the simulations are from the 30-m, 2001 National Land Cover Data dataset (Homer et al. 2007). The data are also resampled (nearest neighbor) to $500 \mathrm{~m}$ and reclassified into corresponding SnowModel land cover and height classes (Table 1).

To illustrate the temporal coverage of snow in SnowModel for these experiments, the spatial average SWE for both the north and south domains are shown in Fig. 2. The SnowModel SWE spatial distributions for the north and south domains for 1 January 2007, which is after the two blizzards, are shown in Fig. 3a and Fig. 3b, respectively. This is to illustrate the effects the geographical features described in sections $4 \mathrm{a}$ and $4 \mathrm{~b}$ have on SnowModel's SWE fields.

\section{d. Assimilation of MODIS snow cover observations}

For the assimilation of the MODIS observations a direct insertion technique is used where the observations are assumed to be perfect. Hereafter, $\mathbf{y}_{m}$ denotes the MODIS observations and $\mathbf{y}_{a}$ for the AMSR-E observations. The observation operators are $\mathbf{h}_{m}(\mathbf{x})$ for MODIS and $\mathbf{h}_{a}(\mathbf{x})$ for AMSR-E. The model SWE is contained in the state vector $\mathbf{x}$.

There are five values that $\mathbf{y}_{m}$ can have: 200 for snowcovered land, 100 for snow-covered frozen water, 50 


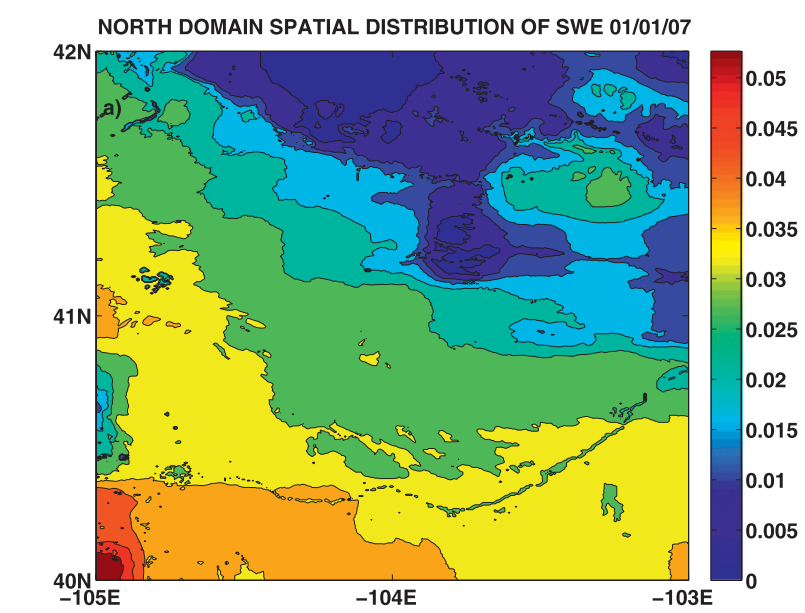

SOUTH DOMAIN SPATIAL DISTRIBUTION OF SWE 01/01/07

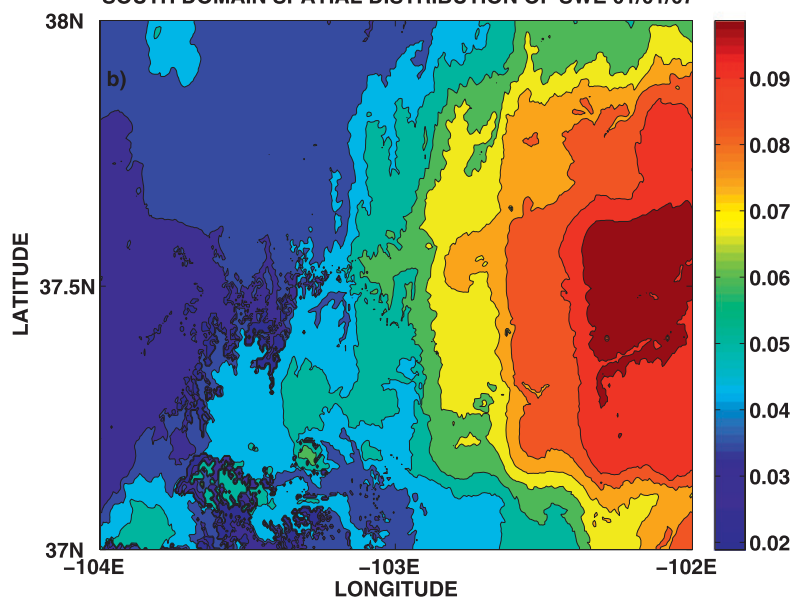

FIG. 3. SnowModel's SWE (m) spatial distribution for 1 Jan 2007 for (a) north domain and (b) south domain.

indicates cloud cover, 37 for unfrozen water, and finally 25 for snow-free land.

Although snow cover is not a state variable in SnowModel, it is possible to create a snow cover variable from the SWE values for each model grid cell. Therefore, if $\mathbf{x}_{i, j}>0$ then $\left[\mathbf{h}_{m}(\mathbf{x})\right]_{i, j}=200$ else $\left[\mathbf{h}_{m}(\mathbf{x})\right]_{i, j}=25$, where $i$ and $j$ are the indices for the model grid points in the latitudinal and longitudinal directions, respectively.

The differences between the model and MODIS snow covers are calculated next, with the following three cases to consider:

- Case 1: Model snow covers equal MODIS.

- Case 2: Add SWE. Model has no snow-cover, MODIS has snow cover.

- Case 3: Remove SWE. MODIS has no snow cover, but the model does.

These are three cases considered in the following function to produce a new value for the model SWE, $\mathbf{x}_{i, j}^{\text {new }}$, respectively:
- if $\mathbf{y}_{m}-\mathbf{h}_{m}(\mathbf{x}) \in[-150,-100,0,12,25]$ then $\mathbf{x}_{i, j}^{\text {new }}=\mathbf{x}_{i, j}^{\text {old }}$,

- if $\mathbf{y}_{m}-\mathbf{h}_{m}(\mathbf{x}) \in[175,75]$ then $\mathbf{x}_{i, j}^{\text {new }}=0.01 \mathrm{~m}$, and

- if $\mathbf{y}_{m}-\mathbf{h}_{m}(\mathbf{x}) \in[-175,-163]$ then $\mathbf{x}_{i, j}^{\text {new }}=0.0$,

where $\mathbf{x}_{i, j}^{\text {old }}$ is the current value for the model SWE at grid cell $i, j$.

As the MODIS snow cover product does not contain information about how much SWE is present, the amount of SWE that is added to the model cells is arbitrary, highlighting the ill-posedness problem with these observations.

\section{e. Assimilation of AMSR-E $25 \mathrm{~km} \times 25 \mathrm{~km} \mathrm{SWE}$ observations}

As mentioned earlier, the spatial resolution of AMSR-E observations is $25 \mathrm{~km} \times 25 \mathrm{~km}$. To assimilate these observations the model equivalent, $\mathbf{h}_{a}(\mathbf{x})$, is calculated by averaging over all the model cell values inside the equivalent $25 \mathrm{~km} \times 25 \mathrm{~km}$ area in the model to the AMSR-E observation. These areas inside the model are referred to as the AMSR-E model domains hereafter.

As with the MODIS observations, a difference- $-\Delta_{a, k}$, ${ }_{m} \equiv\left[\mathbf{y}_{a}-\mathbf{h}_{a}(\mathbf{x})\right]_{k, m}$, where $k$ and $m$ are indices for the AMSR-E observation predictions in the east-west and north-south directions of the model domain areas-is calculated for each AMSR-E observation. As a direct insertion technique is being used here, $\Delta_{a, k, m}$ represents the total amount of SWE to be added or subtracted from the 2500 model cells in the AMSR-E model domain where all cells are treated equally.

Therefore there are three possibilities that this algorithm addresses:

- if $\Delta_{a, k, m}>0$, calculate an average increment $\delta_{a, k, m}=$ $\Delta_{a, k, m} / 2500 . \quad$ Then $\quad \mathbf{x}_{i, j}^{\text {new }}=\mathbf{x}_{i, j}^{\text {old }}+\delta_{a, k, m} \quad$ and $\Delta_{a, k, m}^{\text {new }}=\Delta_{a, k, m}^{\text {new }}+\delta_{a, k, m}$,

- if $\Delta_{a, k, m}=0$ then $\mathbf{x}_{i, j}^{\text {new }}=\mathbf{x}_{i, j}^{\text {old }}$, and

- if $\Delta_{a, k, m}<0$ then calculate $\delta_{a, k, m}$ as above and remove this increment for each model cell inside the AMSR-E model domain.

It should be noted that $\Delta^{\text {new }}$ is initialized as $0 \mathrm{~m}$ and the indices $i$ and $j$ are for the model cells inside the AMSR-E model domains.

However, there are three situations that can occur when removing SWE from a model cell: 1) $\mathbf{x}_{i, j}^{\text {old }}>\delta_{a, k, m}$, 2) $\mathbf{x}_{i, j}^{\text {old }}=\delta_{a, k, m}$, or 3$) \mathbf{x}_{i, j}^{\text {old }}<\delta_{a, k, m}$. For the first two situations the algorithm follows the first two rules above. However, for the third, a counter variable, $t t$, is used to track the number of cells that have values of SWE greater than zero that are available for more SWE to be removed from the model cell on the next iteration if the total amount of SWE removed does not equal $\Delta_{a, k, m}$. For 
the third situation the cell's amount of SWE is added to $\Delta_{a, k, m}^{\text {new }}$ and the cell's SWE value is set to zero; this cell is not available for any further reduction of $\Delta_{a, k, m}$.

After each cell has been checked inside the AMSR-E model equivalent area, $\Delta_{a, k, m}-\Delta_{a, k, m}^{\text {new }}$ is calculated. If $\Delta_{a, k, m}-\Delta_{a, k, m}^{\text {new }}=0$ then the algorithm moves to the next AMSR-E model domain and repeats the processes above. If $\Delta_{a, k, m}-\Delta_{a, k, m}^{\text {new }}<0$ then $\Delta_{a, k, m}=\Delta_{a, k, m}^{\text {new }}$, and $\Delta_{a, k, m}^{\text {new }}=0$, calculate a new increment that is defined as $\delta_{a}$, ${ }_{k, m}=\Delta_{a, k, m} / \mathrm{tt}$, reset $\mathrm{tt}=0$, and repeat all of the above checks until the condition $\Delta_{a, k, m}-\Delta_{a, k, m}^{\text {new }}=0$ is satisfied.

In summary, the MODIS algorithm provides information to the model of where there is a discrepancy in snow coverage and corrects this with some arbitrary increment of SWE added to the model cell. The AMSR$\mathrm{E}$ observations have information of the average SWE over a $25 \mathrm{~km} \times 25 \mathrm{~km}$ area, but do not provide location information for the SWE, as such the algorithm above simply iterates around the AMSR-E model domain until the model matches the AMSR-E observation, treating each cell equally. This highlights the ill-posed nature of assimilating these two sets of observations independently.

\section{f. Combined AMSR-E SWE and MODIS snow cover assimilation}

The combined-observation approach starts by calculating $\mathbf{h}_{m}(\mathbf{x})$ (section $4 d$ ). The next step is to start to calculate $\mathbf{h}_{a}(\mathbf{x})$ (section $4 \mathrm{e}$ ), but now each model cell is checked against its $\left[\mathbf{h}_{m}(\mathbf{x})\right]_{i, j}$ equivalent. If MODIS has detected snow for this model cell and the model has a zero SWE value, then a small amount of SWE is added to that cell (simply to initialize that cell with some nonzero SWE, the magnitude of which shall be adjusted by the AMSR-E SWE information). If there is a cloud present in the MODIS observation cell then that model cell is left untouched. If MODIS sees no snow and the cell has snow then the model cell's SWE is set to zero. The final part of the initialization is to calculate $\left[\mathbf{h}_{a}(\mathbf{x})\right]_{k, m}$.

The next part of the algorithm is to calculate the average increment for all 2500 model cells. The combined algorithm follows the same iterative procedure from section $4 \mathrm{e}$ but now each model cell is checked against the MODIS observation for that cell to see if it is snow covered or not. This determines whether or not SWE can be added or removed, but also how much. However, it is possible that by subtracting the increment a model cell could become snow free yet MODIS may have detected snow here. Therefore, the algorithm removes half of the increment (again this is arbitrary but enables the cell to contribute to the SWE reduction). An algorithmic description of this method is in the appendix.

\section{g. MODIS and combined MODIS and AMSR-E assimilation}

This final assimilation scheme performs the MODIS assimilation scheme from section $4 \mathrm{~d}$ on the days that there are no AMSR-E observations and then the combination scheme from section $4 \mathrm{f}$ when both sets of observations are available. Hence, this approach is not a redundant usage of MODIS data, but rather, a maximal usage of satellite data where and when they are available for assimilation.

\section{Results}

In this section results are presented from the four assimilation schemes described in sections $4 \mathrm{~d}-\mathrm{g}$ for both the north and south domains. The observations are assimilated at the local noon time step, which is an output time for the model, and which allows the innovations between the model and the observations to be calculated.

\section{a. Root-mean-square differences results}

In this first section of results, plots of the root-meansquare differences (RMSD) defined as

$$
\operatorname{RMSD}=\frac{1}{\sqrt{M \times N}} \sqrt{\sum_{i=1}^{M} \sum_{j=1}^{N} a_{i, j}^{2}}
$$

are presented in Fig. 4, where $\mathbf{A} \in \mathbf{R}^{M \times N}, M$ is the number of grid points in the longitudinal direction, $N$ is the number of grid points in the latitudinal direction, and $a_{\mathrm{i}, \mathrm{j}}$ are the entries in $\mathbf{A}$. For the results presented in Fig. 4, A is the matrix of the difference in the SWE from the control run, which is a run of the model without any assimilation, and the assimilation runs for each domain. This statistic is a measure of the average change in the SWE (in meters) for the model cells for the different schemes compared to the control run.

The interesting feature that is present in Fig. 4 is the size of the average increment for the AMSR-E-only assimilation schemes between the two domains (Figs. 4a and $4 \mathrm{e}$, respectively). The maximum increment for the south domain is over a factor of 2 larger than the equivalent increment for the north domain. While it is clear that this increment is smaller than those associated with the MODIS-based schemes, this indicates that in the south domain there could be an underestimation of the SWE by the model, but that the snow cover is fairly consistent with the MODIS observations for most of the experimental time period. This is reinforced by comparing the results for the MODIS-based schemes for the 
NORTH DOMAIN
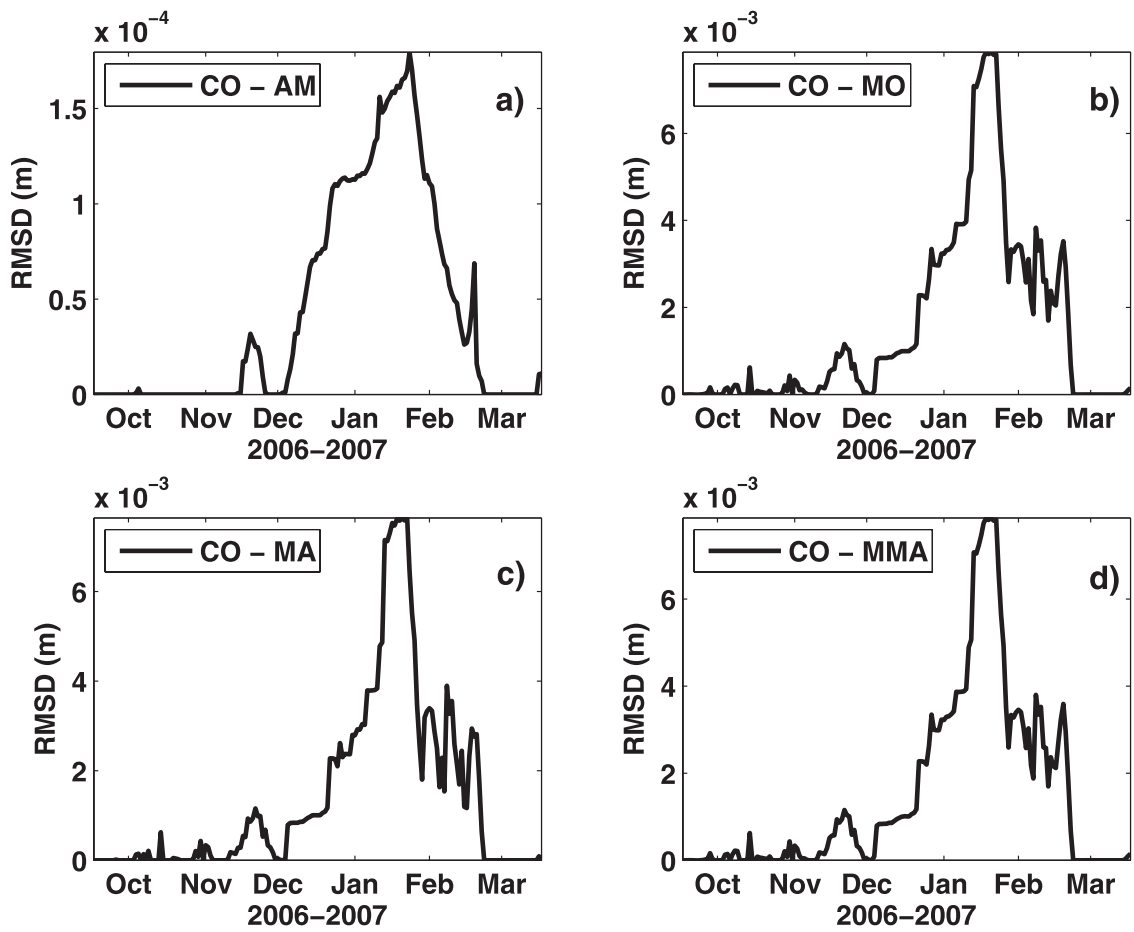

SOUTH DOMAIN
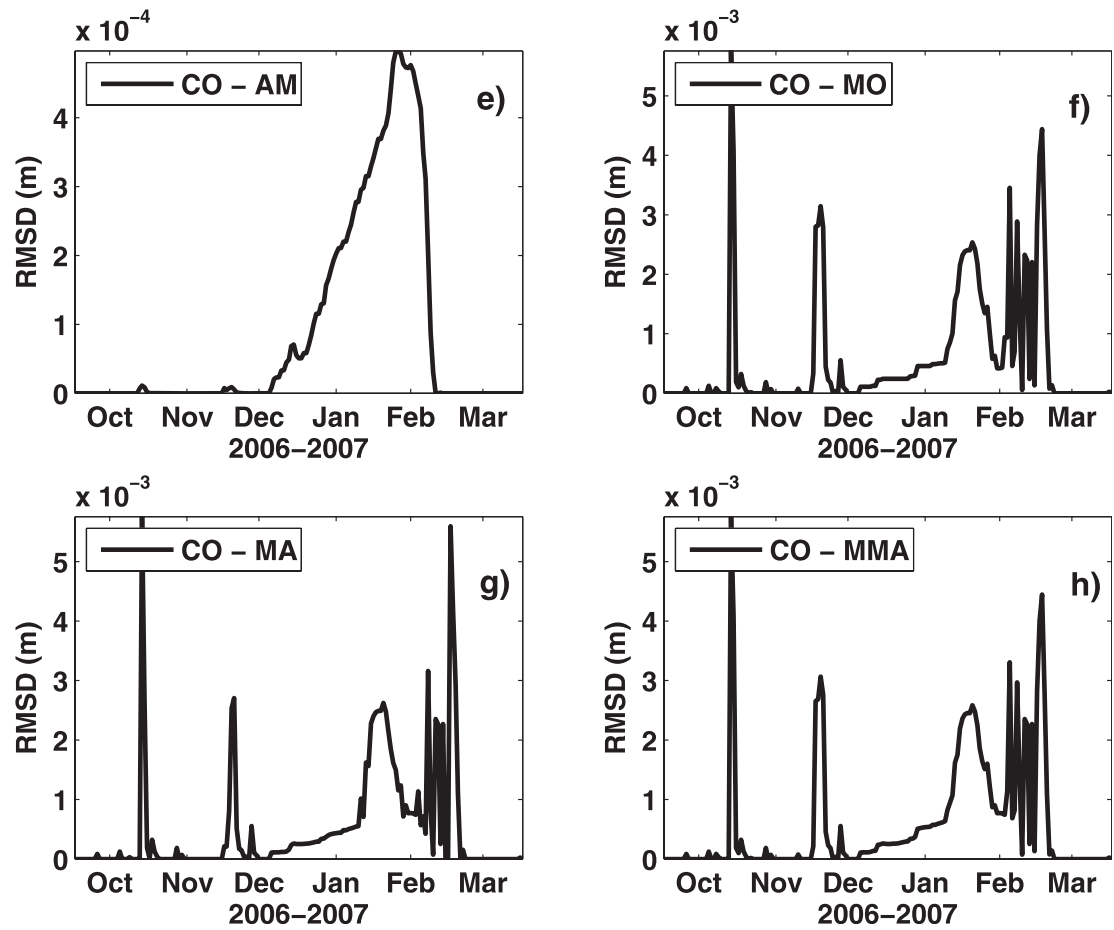

FIG. 4. Figure of the RMSD (m) between the control run and the four assimilation approaches for (a)-(d) the north domain and (e)-(h) the south domain, where AM stands for AMSR-E assimilation, MO is for MODIS assimilation, MA stands for the MODIS and AMSRE assimilation when both are available, and MMA stands for MODIS and the combined assimilation. 
north domain (Figs. 4b-d) with those for the south domain (Figs. $4 \mathrm{f}-\mathrm{h}$ ). When removing the spikes in the south domain from the event in October, it is clear that the maximum RMSD is a factor of 2 smaller for the south domain than the north domain, where for the north domain the maximum is almost the same size as the arbitrary increment from the MODIS scheme of $0.01 \mathrm{~m}$. This indicates that there are quite a few cells in the control run that are snow clear yet MODIS indicates that there is still snow cover there. This feature is not present in the results for the MODIS-based schemes for the south domain, suggesting that the snow cover is better modeled here, but that the amount of SWE is not as consistent with the AMSR-E observations.

It should be noted that similar work using more advanced data assimilation methods, with a different numerical model, in different areas and over different times, to the work presented here is shown in Andreadis and Lettenmaier (2006), but where the assimilation of the SWE observations degraded the model runs.

\section{b. MODIS comparison}

The results that are presented in this section assess the change in the total percentage disagreement in snow coverage from the control and assimilation runs with the MODIS observation before they are assimilated. The percentage is calculated from the total number of cloudfree pixels in the MODIS observations for each domain. A summary of the cloud coverage percentages in bins of $10 \%$ is presented for both domains in Table 3 .

The north domain's results from this assessment are presented in Fig. 5a. The interesting feature here is the increase of 18 days with a less than a $10 \%$ disagreement in the snow cover compared to the control run. It is also clear that the reduction in disagreement for the schemes involving assimilating MODIS observations has a large impact on reducing the snow cover disagreement $24 \mathrm{~h}$ later in the $10 \%-50 \%$ range. The specific reductions relative to the control run are shown in Fig. 5c. Therefore it appears that an increment of $0.01 \mathrm{~m}$ of SWE added in the MODIS-based scheme is approximately the correct amount, such that the melt rates in the model are not able to remove all the SWE added by the next observation time for this domain.

For the south domain (Fig. 5b), the control run has a better agreement with the MODIS images than the north domain. However, there is still a positive increase in the number of days with less than a $10 \%$ disagreement with the future MODIS observations when MODIS data is assimilated. Figure $5 \mathrm{~d}$ shows the bar graph of the differences between the control run and the four assimilation schemes. Unlike with the north domain, it is clear that the amount of SWE chosen a priori for these
TABLE 3. Total number of days for each cloud-covered percentage range of the MODIS observations for the north and south domains.

\begin{tabular}{ccc}
\hline \hline Cloud coverage $\%$ & North domain & South domain \\
\hline $0-10$ & 18 & 52 \\
$11-20$ & 12 & 14 \\
$21-30$ & 15 & 10 \\
$31-40$ & 19 & 12 \\
$41-50$ & 16 & 12 \\
$51-60$ & 9 & 17 \\
$61-70$ & 17 & 7 \\
$71-80$ & 15 & 6 \\
$81-90$ & 14 & 10 \\
$91-100$ & 46 & 41 \\
\hline
\end{tabular}

experiments is not large enough, as suggested by the increase in the number of days with between $11 \%$ and $30 \%$ disagreement. However, including the AMSR-E observations appears to have a positive impact when combined with the MODIS observations, allowing the possiblity of a larger increment from the arbitrarily chosen $0.01-\mathrm{m}$ increment of SWE to be added.

It should be noted that there are more days for the south domain where the MODIS images and the control runs agree than for the north domain. This is consistent with the results from the RMSD section.

Therefore, it appears that an increment of $0.01 \mathrm{~m}$ of SWE added into the model may be suboptimal for the south domain. To assess what may be the optimal increment for the south domain, and to show that $0.01 \mathrm{~m}$ is a near-optimal choice for the north domain, results are presented for the MODIS-only assimilation scheme with increments of $0.005 \mathrm{~m}$ (half), $0.01 \mathrm{~m}$ (modcontrol), or $0.02 \mathrm{~m}$ (double). These results are in Figs. $6 \mathrm{a}$ and $6 \mathrm{~b}$ for the north and south domains, respectively.

The feature to note for the north domain is that the 0.005- $\mathrm{m}$ increment appears to be suboptimal compared to the results for the $0.01-\mathrm{m}$ increment in the $0 \%-10 \%$ disagreement bin. The choice of $0.02 \mathrm{~m}$ for the increment has a positive impact by reducing one of the nearly $100 \%$ disagreement days.

For the south domain it appears in Fig. 6b that both 0.005- and 0.01-m increments are suboptimal. However, using increments of $0.02 \mathrm{~m}$ appears to be nearer to an optimal choice, where there are reductions in the larger disagreements bins as well as a doubling of the number of days with a $20 \%$ or less disagreement with the MODIS snow cover observations.

\section{c. Snow-depth comparisons to station data}

In this subsection snow-depth outputs from the model and the assimilation runs are compared to station data in both domains. There is no reported SWE station data 

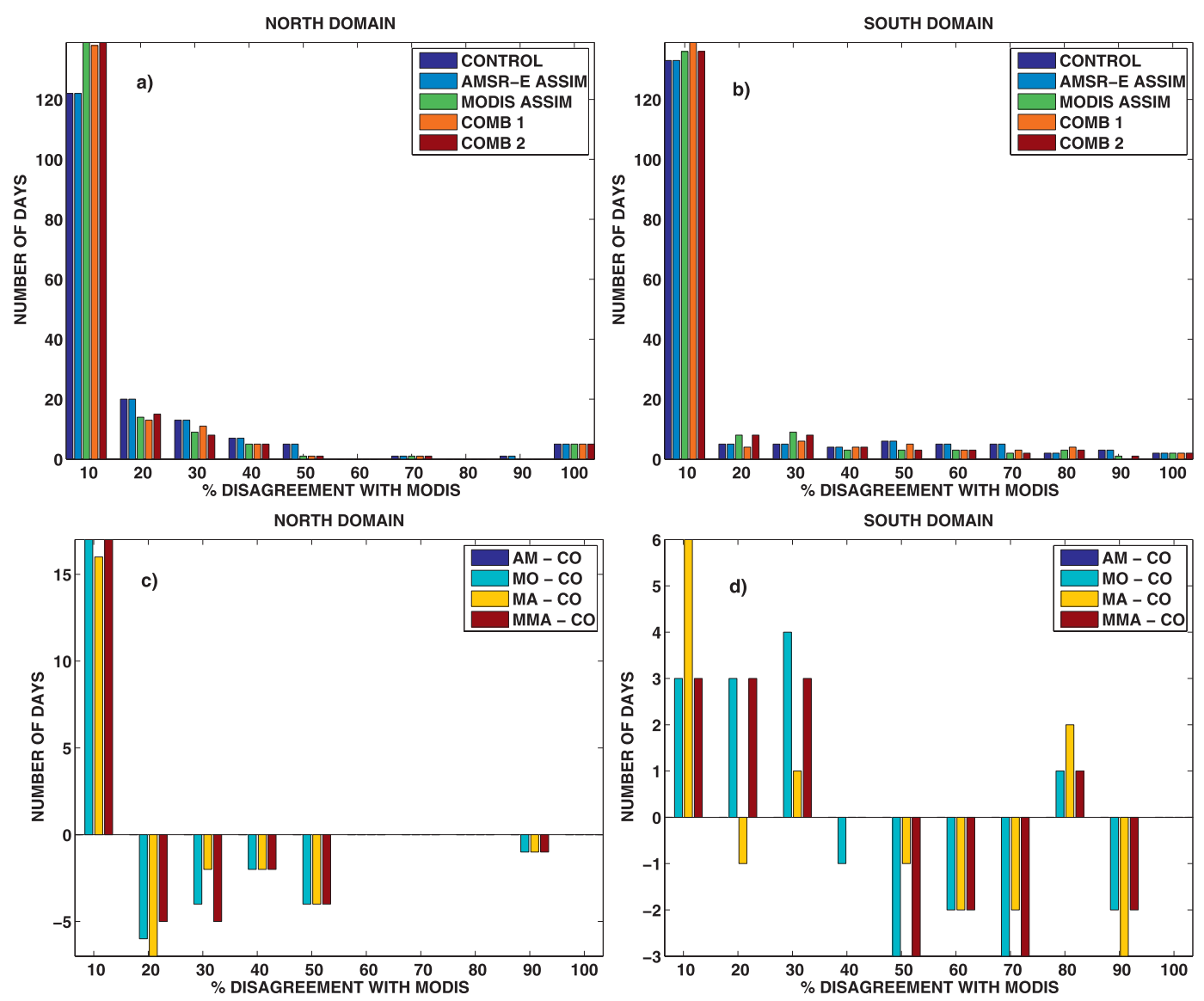

FIG. 5. (a) Plot of the number of days in the north domain that each of the four assimilation schemes and the control run have a specific \% disagreement in snow cover with the MODIS cloud clear pixels where comb1 $=$ MA and comb2= MMA. (b) This plot description is similar to that in (a) but for the south domain. (c) Plot of the changes in the \% disagreement in the MODIS snow cover observations from the control run for the north domain. (d) This plot description is similar to that in (c) but for the south domain.

available in either domain for the period of the experiments. However, in the assimilation schemes the snow depth is updated with the new SWE amounts and snowdepth observations are available in the National Oceanic and Atmospheric Administration climatological data reports, which are produced monthly for each state, available at http://www7.ncdc.noaa.gov/IPS/cd/cd.html.

In the north domain the snow depths from the assimilation runs are compared to the Greeley University of Northern Colorado (UNC) and Akron stations in Colorado, Chugwater, Pine Bluffs 5W, and La Grange stations in Wyoming and the Scottsbluff station in Nebraska.

The results for the north domain are shown in Fig. 7. Figures $7 \mathrm{a}$ and $7 \mathrm{~b}$ are the two Colorado stations in the order mentioned above. The first feature is the pattern of melt and accumulation appear similar to the stations' data. However, the snow depth is underestimated at both stations. This smaller depth will affect the physics in the model and will be different to the situation on the ground because of feedback from temperature. An interesting feature in late February is when the model, MODIS, and AMSR-E detect snow and SWE yet the Greeley station does not report snow. The assimilation schemes that use MODIS observations allow for the snow to be removed the next day, while the AMSR-E assimilation keeps the SWE for two more days. The results for the Akron station (Fig. 7b) show that all of the assimilation and control simulations agree closely, shown by only the last two colors on the legend being visible; this is true for all panels in Figs. 7 and 8, but the control run is similar to the AMSR-E run and does not show in the figures.

The results from the three Wyoming stations are shown in Figs. 7c-e in the order listed above. From the Chugwater station results (Fig. 7c) it appears that snow depth is underestimated for part of the season, for the Pine Bluffs results there appears better agreement with 

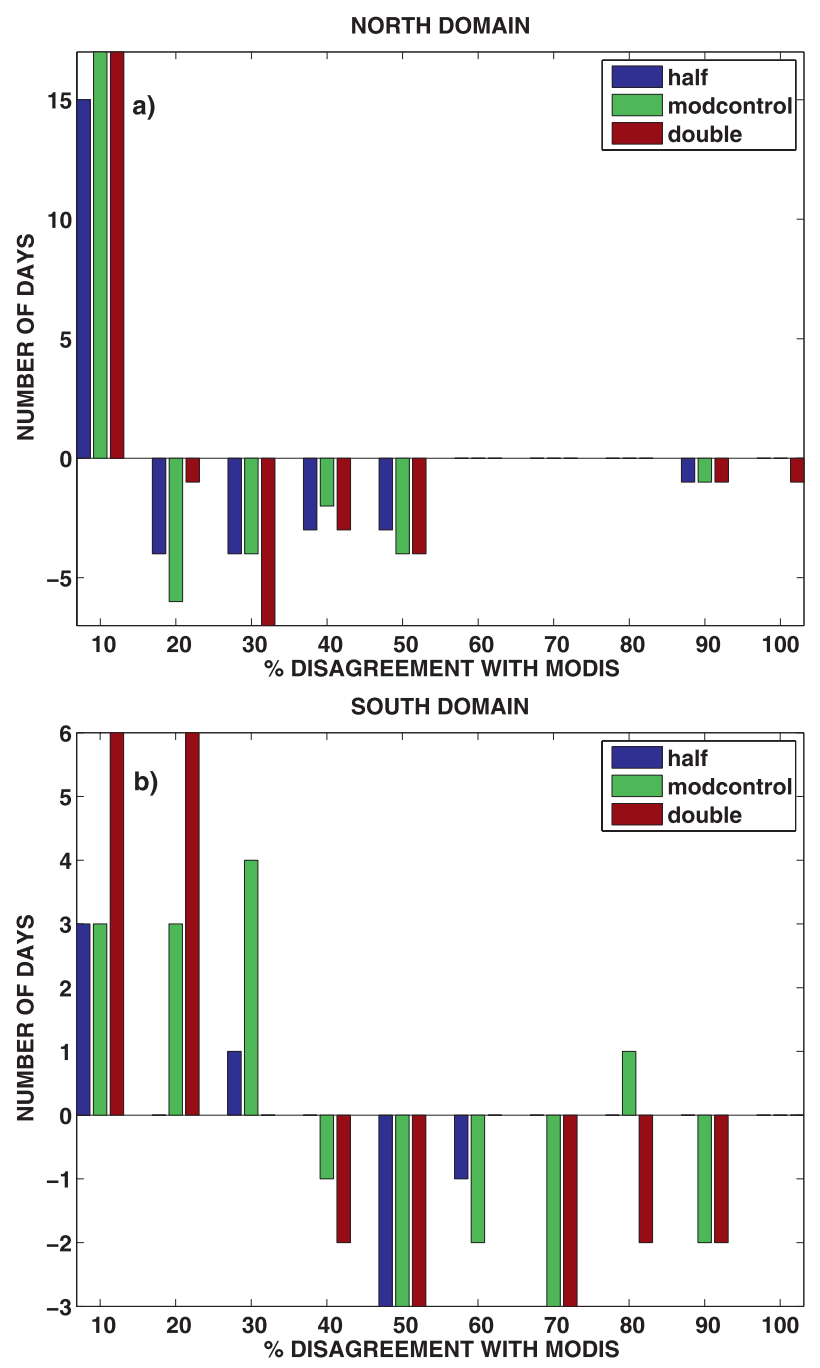

FIG. 6. Plot of the changes in the disagreement with the MODIS snow cover observations from the control run for three different choices for the increment for (a) north domain and (b) south domain.

the station data, while at the La Grange station there appears a large discrepancy between the model and station data. It should be noted that point source data are not the same as a cell value, and that none of the stations are located as the exact coordinates as the model cell's center.

For the first two Wyoming stations the accumulation/ melt patterns of the model appear quite similar to the station data but as good agreement with the third station. However, when the melting occurs the MODIS base schemes match the station data quite closely for Pine Bluffs, the delay in the Chugwater results is due to the MODIS observation at this point being cloud covered, which means that the MODIS-based schemes are designed to leave the model unchanged if this occurs.
The interesting result here is that the AMSR-E and control run continue with the snow cover at least seven more days after the station reports no snow.

The final station in Wyoming is La Grange (Fig. 7e). This station shows a very clear difference between the model and the station data. The results from this station do highlight that while the snow depth is underestimated, the assimilation schemes are all increasing the SWE and, hence, the snow depth compared to the control run. The two assimilation runs where MODIS is assimilated every day show an improvement, albeit small, compared to the other assimilation schemes and the control run.

The results for the last station for the north domain, Scottsbluff in Nebraska, are shown in Fig. 7f. From this figure it is clear that the model, and assimilation schemes, all underestimate the snow depth here, but are fairly consistent with the melt-accumulation pattern at this location. An interesting feature of the plot is in October where it appears that a small snow event is missed by all of the assimilation schemes. The reason for this is that the AMSR-E did not have a complete observation of the north domain that day, and the MODIS image was cloud covered at the equivalent pixel.

In the south domain there are two stations that are used to assess the assimilation schemes: these are Kim $15 \mathrm{NNE}$ and Walsh. The Kim station is in the west of the domain and the Walsh station is near the large snow accumulation in the east of the domain from the second blizzard.

The results for the Kim station are in Fig. 8a. It appears that all of the assimilation schemes and the control run are similar in underestimating the snow depth by nearly a factor of 3 and have the general same pattern, given the physics associated with assuming a snowpack that is this deep, which is not the same as the observed. The melt events start to occur at approximately the same time but are quicker than observed. The results for the Walsh station are in Fig. 8b, where it appears that at this location there is not a large difference between the control run and the assimilation schemes, but it does highlight that SnowModel is performing fairly well at this location with the melt-accumulation pattern, but again has a slight underestimation of the snow depth. These plots also contain the results from MODIS assimilation with the $0.02-\mathrm{m}$ increment. It can clearly be seen in both figures that this scheme is introducing SWE to the model cells but that the model is melting it away quickly.

As a final remark about these results, it should be noted that snow depth is not assimilated in the experiments, and that the average change to the SWE is over 2500 model cells for each AMSR-E model domain, 

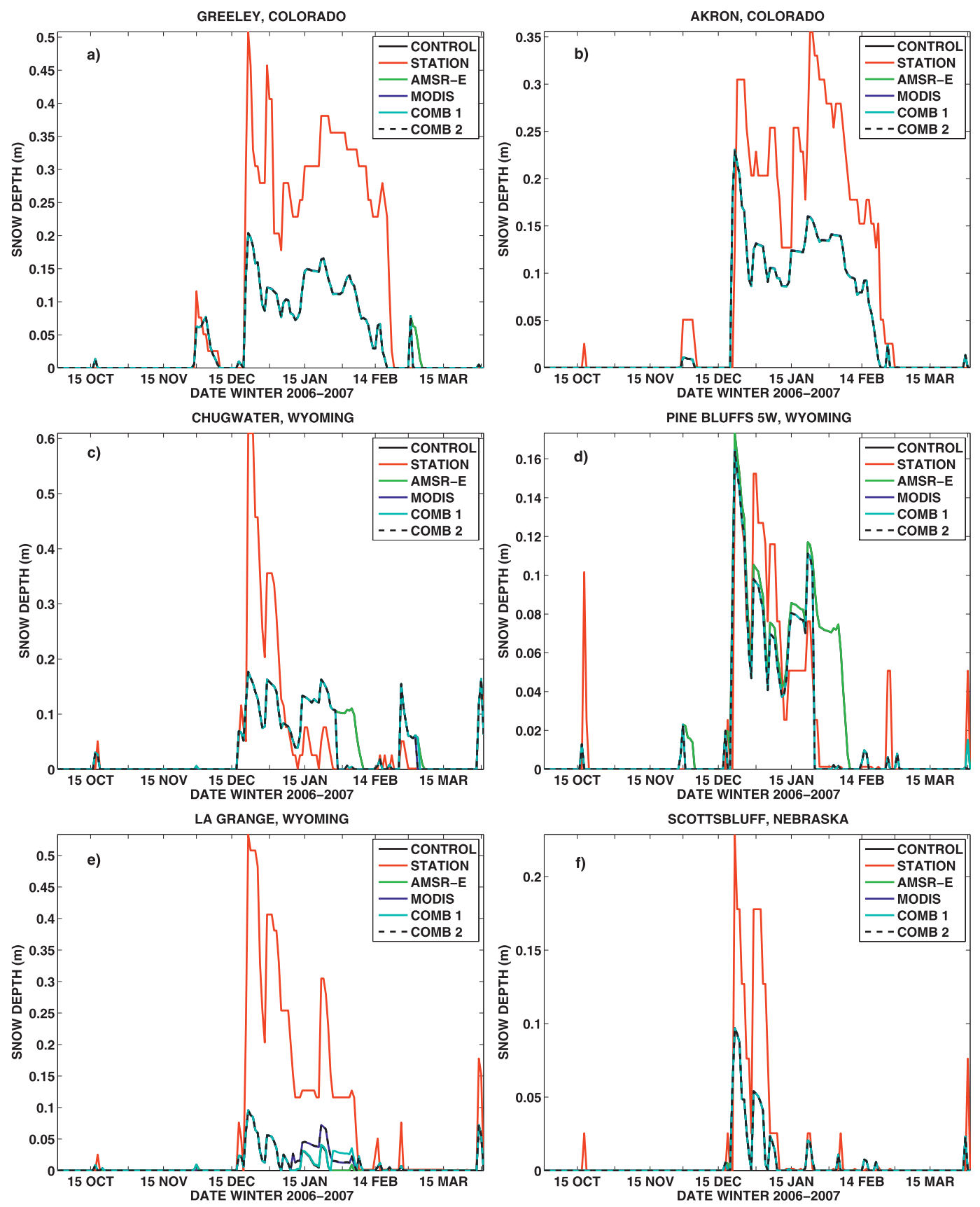

FIG. 7. Plot of north domain station snow-depth data with the control and assimilation runs snow depth for (a) Greeley and (b) Akron, Colorado; (c) Chugwater, (d) Pine Bluffs, and (e) La Grange, Wyoming; and (f) Scottsbluff, Nebraska; where the black solid line is the control run, the red solid line is the station data, solid green line is the AMSR-E-only assimilation, blue solid line is the MODIS only, the cyan solid line is the first combined, and finally the dashed black line is the second combination scheme.

which is where the snow-depth changes are coming from, and hence at an individual cell point the amount needed specifically there cannot come from MODIS snow cover or AMSR-E SWE. Therefore, indicating a third set of observations are required, specifically snow depth.

\section{Discussion and conclusions}

\section{a. Discussion}

In this subsection, some caveats are provided about this work along with some future work ideas about transferability of these techniques along with some ideas 

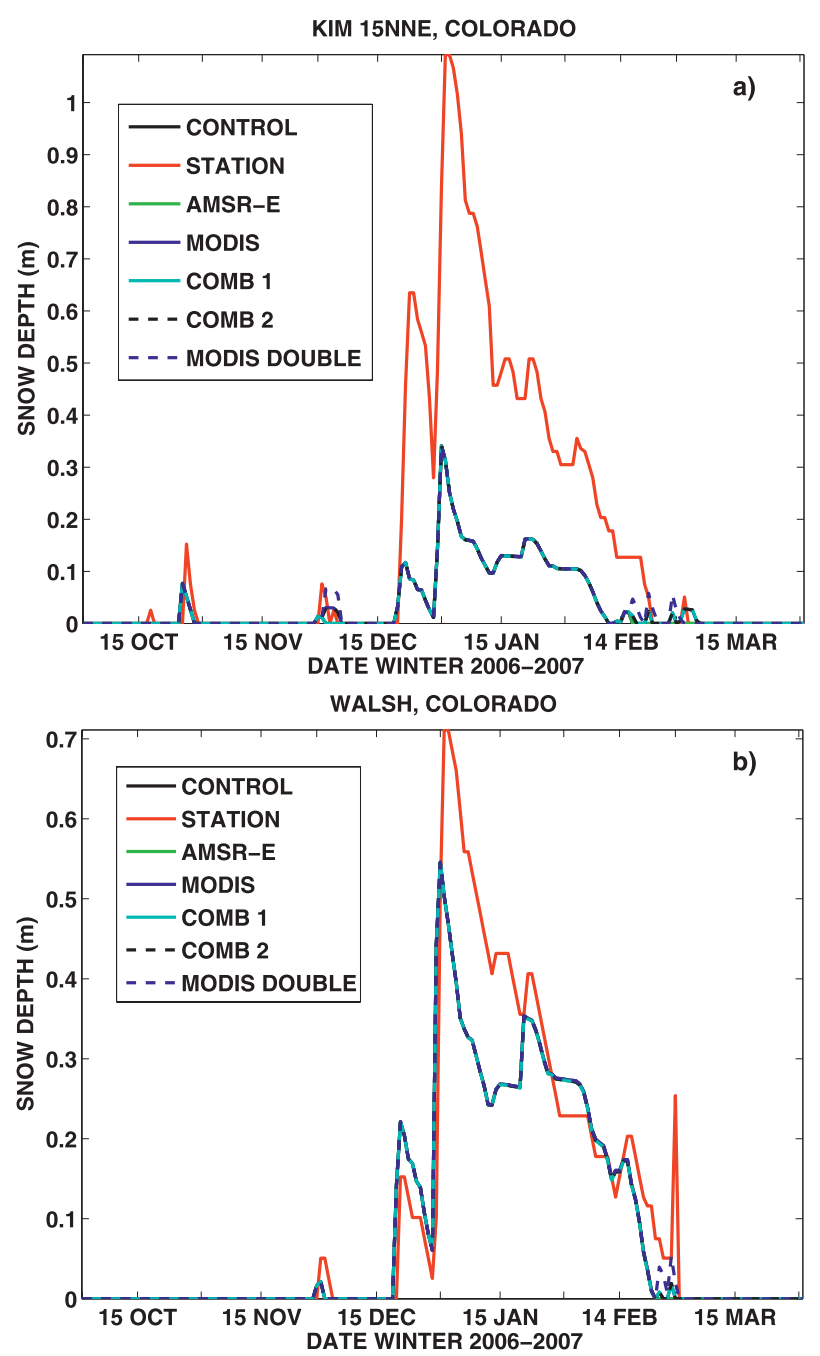

FIG. 8. Plot of south domain station snow-depth data with the control and assimilation snow depths for (a) Kim and (b) Walsh, Colorado, where the black solid line is the control run, the red solid line is the station data, solid green line is the AMSR-E-only assimilation, blue solid line is the MODIS only, the cyan solid line is the first combined, the dashed black line is the second combination scheme, and finally the dashed blue line is the $0.02-\mathrm{m}$ increment MODIS-only assimilation.

on how to constrain the amount of influence that the observations have on the increments added or subtracted from the model's SWE amounts.

The techniques presented in this manuscript are of the direct insertion family. These techniques are computationally inexpensive and reasonably quick. In the work here, the SWE amounts were updated with a rule-based iterative approach, trying to utilize the binary data from the MODIS snow cover observations in conjunction with the SWE observations. There are, however, more advanced techniques that could be used to update the SWE: three- or four-dimensional variational data assimilation, or ensemble Kalman filter, for example.

The direct insertion techniques used in this paper are applicable to any snow evolution model; however, it should be noted that the direct insertion techniques assume perfect observations, which is not true for the two observation sets used in the experiments shown. These errors should be incorporated into some form of weighting of the observations in a future application.

This weighted approach could address the transferability of these techniques to areas where there are tree canopies, which are known to cause errors in MODIS and AMSR-E observations. If the vegetation index of SnowModel, or any land surface snow evolution model, indicates that a tree canopy is present, then unless the snow is deeper than the trees, assume the model is more accurate in these areas. Again the same reasoning could be used for the morphology of the snow. If it is known that melting is occurring and this causes errors with the AMSR-E observations then weight the model more and reduce the impact of the AMSR-E observations at this time.

After taking into account the errors associated with the MODIS observations, the problem still remains how much SWE to introduce into the model cells if there is a negative difference between the model and MODIS. One technique would be to use the vegetation index in Table 1 to provide a minimum amount of SWE to be added to the model cell such that the snow depth is greater than the vegetation-holding depth. This same information could be used as the criteria for the removal of snow for the AMSR-E-based techniques. Currently this is set to half of the model cell's SWE value, but instead could be set so that the SWE in the cell is below the MODIS detection threshold and then this cell would be treated as a zero cell for the remainder of the iterations. Also what should be taken into account is what size increment is needed relative to the external forcing; that is, if the snow is in a melt phase or an accumulation phase then the increment required may not be the same and as such this information could be used to define the size of the increment.

One feature that comes from using a direct insertion technique is the fact that snowpack information is not used to allocate the SWE increments in the AMSR-Ebased algorithms. Therefore a way to optimize the allocation of SWE increments would be to use this model information to have another weighting for the model cells' allocation of SWE due to snowpack depth. However, for the MODIS-only observation assimilation scheme this information is not needed as it is snow cover discrepancies that are being corrected. 


\section{b. Conclusions}

In this paper four simple and computationally inexpensive direct insertion data assimilation schemes to assimilate MODIS snow cover observations and/or AMSR-E SWE observations into a high-resolution snow evolution model have been presented. These four schemes were tested over two domains: one in the southeastern corner of Colorado and the other in the tristate area of Colorado, Wyoming, and Nebraska for the winter of 2006/07. As these techniques are direct insertion based, an arbitrary increment for the MODISbased assimilation schemes had to be allocated. For the first set of experiments this was set to $0.01 \mathrm{~m}$.

The experiments were assessed against three different measures: root-mean-square differences between the assimilation runs and the control, matching the cloudfree MODIS image $24 \mathrm{~h}$ later, and finally against snowdepth data from station data inside the two domains. It was shown from the RMSD results that there appeared to be an underestimation of the snow cover area in the north domain - this was indicated by size of the RMSD for the MODIS-based scheme, being almost the same size as the arbitrary increment. Whereas for the south domain, the RMSD was smaller for all four schemes compared to the north domain, and never close to the arbitrary increment-almost a factor of 3 smaller for a majority of the time. This suggests that in the south domain there is better agreement with MODIS snow cover observations, but an underestimation of SWE.

The conclusion above was reinforced by the 24-h-later MODIS cloud clear snow cover comparisons. For the north domain there was an increase of 18 days with a less than $10 \%$ disagreement in snow cover through using MODIS observations, which is a $15 \%$ improvement in snow coverage, relative to the MODIS images. In the south domain there appears to be a better snow cover agreement without the assimilation of MODIS observations than for the north domain, and there was only a $5 \%$ improvement in snow cover when MODIS observations were assimilated.

The final measure of the performance of the assimilation schemes was to compare the snow depth from the schemes and the control to station data from the two domains. It was shown that while the general accumulation and melt patterns were fairly consistent, the snow depth was underestimated at most locations by up to a factor of 5 for some stations. This finding would indicate that for a snow-depth improvements, given the boundary conditions for SnowModel, the assimilation of snow cover, SWE, and snow depth combined may yield the best method for improving SnowModel's snowdepth representations.
It should be noted that in Liston and Hiemstra (2008) it is mentioned that the precipitation forcings could be causing SnowModel to underestimate the snow depth as the amount of precipitation entering the model is underestimated. Therefore, SnowModel can only work with the boundary conditions that it is provided-if the atmospheric forcings are incorrect then the associated physics of the snow evolution will be constrained by this accuracy as well as the interactions of the errors in the numerics and these meteorological forcings.

Acknowledgments. SJF is grateful for the help from Mr. John Forsythe at CIRA in understanding and inverting the different projections that the MODIS and AMSR-E observations come in. We are grateful for the useful reviews of this manuscript by Noah Molotch and the four other anonymous reviewers. This work was supported by the NASA Grant NNX08AV21G.

\section{APPENDIX}

\section{Combined MODIS and AMSR-E Assimilation Algorithm Description}

As mentioned in section $4 \mathrm{f}$, this approach calculates an average increment to be added or subtracted from the cells in the AMSR-E model domain, but now there is the extra constraint of matching the snow cover observations from MODIS. There are three situations that arise involving the increment, denoted here as $\delta_{c, k, m}$, and the model cell's SWE amounts in this algorithm and they are described below.

$$
\begin{aligned}
& \text { If } \mathbf{x}_{i, j}^{\text {old }}+\delta_{c, k, m}>0 \quad \text { then } \\
& \text { If } \mathbf{y}_{\mathbf{m} i, j}=200, \mathbf{y}_{\mathbf{m} i, j}=100 \quad \text { or } \quad \mathbf{y}_{\mathbf{m} i, j}=50 \text { then } \\
& \mathbf{x}_{i, j}^{\text {new }}=\mathbf{x}_{i, j}^{\text {old }}+\delta_{c, k, m}, \Delta_{c, k, m}^{\text {new }}=\Delta_{c, k, m}^{\text {new }}+\delta_{c, k, m}, t t=t t+1
\end{aligned}
$$

Else

$$
\mathbf{x}_{i, j}^{\text {new }}=\mathbf{x}_{i, j}^{\text {old }}
$$

\section{End If}

Else if $\mathbf{x}_{i, j}^{\text {old }}+\delta_{c, k, m}=0$ then

$$
\begin{aligned}
& \text { If } \mathbf{y}_{\mathbf{m} i, j}=25 \quad \text { or } \quad \mathbf{y}_{\mathbf{m} i, j}=37 \text { then } \\
& \mathbf{x}_{i, j}^{\text {new }}=\mathbf{x}_{i, j}^{\text {old }}+\delta_{c, k, m}, \Delta_{c, k, m}^{\text {new }}=\Delta_{c, k, m}^{\text {new }}+\delta_{c, k, m}
\end{aligned}
$$

Else

$$
\mathbf{x}_{i, j}^{\text {new }}=\mathbf{x}_{i, j}^{\text {old }} / 2, \Delta_{c, k, m}^{\text {new }}=\Delta_{c, k, m}^{\text {new }}-\mathbf{x}_{i, j} / 2, t t=t t+1
$$




\section{End If}

Else

$$
\begin{gathered}
\text { If } \mathbf{y}_{\mathbf{m} i, j}=200, \mathbf{y}_{\mathbf{m} i, j}=100 \quad \text { or } \quad \mathbf{y}_{\mathbf{m} i, j}=50 \text { then } \\
\mathbf{x}_{i, j}^{\text {new }}=\mathbf{x}_{i, j}^{\text {old }} / 2, \Delta_{c, k, m}^{\text {new }}=\Delta_{c, k, m}^{\text {new }}-\mathbf{x}_{i, j} / 2, t t=t t+1
\end{gathered}
$$

Else

$$
\mathbf{x}_{i, j}^{\text {new }}=0, \Delta_{c, k, m}^{\text {new }}=\Delta_{c, k, m}^{\text {new }}+\mathbf{x}_{i, j}^{\text {old }}
$$

\section{End If}

\section{End If}

Because of the extra constraint of satisfying the MODIS snow cover observations, a different set of stopping criteria for $\Delta_{c, k, m}-\Delta_{c, k, m}^{\text {new }}$ are required. The criterion $\Delta_{c, k, m}-\Delta_{c, k, m}^{\mathrm{new}}=0$ is used, but if this cannot be satisfied because of MODIS constraining the number of snow-free cells, then the extra criterion of $t t=0$, which is stating that if there are now more cells available to be used then exit this AMSR-E model domain.

\section{REFERENCES}

Andreadis, K. M., and D. P. Lettenmaier, 2006: Assimilating remotely sensed snow observations into a macroscale hydrology model. Adv. Water Resour., 29, 872-889.

Chang, A. T. C., J. L. Foster, and D. K. Hall, 1987: Nimbus-7 derived global snow cover parameters. Ann. Glaciol., 9, 39-44.

,,,--- B. E. Goodison, A. E. Walker, and J. R. Metcalfe, 1997: Snow parameters derived from microwave measurements during the BOREAS winter field experiment. J. Geophys. Res., 102 (D24), 29 663-29 671.

Clifford, D., 2010: Global estimates of snow water equivalent from passive microwave instruments: History, challenges and future developments. Int. J. Remote Sens., 31, 3707-3726.

Cline, D. W., R. C. Bales, and J. Dozier, 1998: Estimating the spatial distribution of snow in mountain basins using remote sensing and energy balance modeling. Water Resour. Res., 34, 1275.

De Lannoy, G. J. M., R. H. Reichle, P. R. Houser, K. R. Arsenault, N. K. C. Verhoest, and V. R. N. Pauwels, 2010: Satellite-scale snow water equivalent assimilation into a high-resolution land surface model. J. Hydrometeor., 11, 352-369.

Durand, M., N. P. Molotch, and S. A. Margulis, 2008: A Bayesian approach to snow water equivalent reconstruction. J. Geophys. Res., 113, D20117, doi:10.1029/2008JD009894.

Foster, J. L., C. Sun, J. P. Walker, R. Kelly, A. Chang, J. Dong, and H. Powell, 2005: Quantifying the uncertainty in passive microwave snow water equivalent observations. Remote Sens. Environ., 94, 187-203.

Goa, Y., H. J. Xie, N. Lu, T. D. Yao, and T. G. Liang, 2010: Toward advances daily cloud-free snow cover and snow water equivalent products from Terra-Aqua MODIS and Aqua AMSR-E measurements. J. Hydrol., 385, 23-35.
Hall, D. K., and G. A. Riggs, 2007: Accuracy assessment of the MODIS snow products. Hydrol. Processes, 21, 15341547.

Homer, C., and Coauthors, 2007: Completion of the 2001 National Land Cover Database for the conterminous United States. Photogramm. Eng. Remote Sens., 73, 337-341.

Kelly, R., 2009: The AMSR-E snow depth algorithm: Description and initial results. J. Remote Sens. Soc. Japan, 29, $307-$ 317.

Kuchment, L. S., P. Romanov, A. N. Gelfan, and V. N. Demidov, 2010: Use of satellite-derived data for characterization of snow cover and simulation of snowmelt runoff through a distributed physically based model of runoff generation. Hydrol. Earth Syst. Sci., 14, 339-350.

Liang, T. G., X. T. Zhang, H. J. Xie, C. X. Wu, Q. S. Feng, X. D. Huang, and Q. G. Chen, 2009: Toward improved daily snow cover mapping with advanced combination of MODIS and AMSR-E measurements. Remote Sens. Environ., 112, 3750-3761.

Liston, G. E., 1999: Interrelationships among snow distribution, snowmelt, and snow cover depletion: Implications for atmospheric, hydrologic, and ecologic modeling. J. Appl. Meteor., 38, 1474-1487.

, 2004: Representing subgrid snow cover heterogeneities in regional and global models. J. Climate, 17, 1381-1397.

- and D. K. Hall, 1995: An energy balance model of lake ice evolution. J. Glaciol., 41, 373-382.

, and M. Sturm, 1998: A snow-transport model for complex terrain. J. Glaciol., 44, 498-516.

— system (SnowModel). J. Hydrometeor., 7, 1259-1276.

- and - 2006b: A meteorological distribution system for high-resolution terrestrial modeling (MicroMet). J. Hydrometeor., 7, 217-234.

and C. A. Hiemstra, 2008: A simple data assimilation scheme for complex snow distributions (SnowAssim). J. Hydrometeor., 9, 989-1004.

, and S. H. Mernild, 2012: Greenland freshwater runoff. Part I: A runoff routing model for glaciated and nonglaciated landscapes (HydroFlow). J. Climate, 25, 5997-6014.

$\longrightarrow$, R. B. Haehnel, M. Sturm, C. A. Hiemstra, S. Berezovskaya, and R. D. Tabler, 2007: Simulating complex snow distributions in windy environments using SnowTran-3D. J. Glaciol., 54, 241-256.

Markus, T., D. C. Powell, and J. R. Wang, 2006: Sensitivity of passive microwave snow depth retrievals to weather effects and snow evolution. IEEE Trans. Geosci. Remote Sens., 44, 68-77.

Mitchell, K. E., and Coauthors, 2004: The multi-institution North American Land Data Assimilation System (NLDAS): Utilizing multiple GCIP products and partners in a continental distributed hydrological modeling system. J. Geophys. Res., 109, D07S90, doi:10.1029/2003JD003823.

Molotch, N. P., 2009: Reconstructing snow water equivalent in the Rio Grande headwaters using remotely sensed snow cover data and a spatially distributed snowmelt model. Hydrol. Processes, 23, 1076-1089.

- , and S. A. Margulis, 2008: Estimating the distribution of snow water equivalent using remotely sensed snow cover data and a spatially distributed snowmelt model: A multi-resolution, multi-sensor comparison. Adv. Water Resour. Climate, 131, 1503-1514.

Pulliainen, J., 2006: Mapping of snow water equivalent and snow depth in boreal and sub-arctic zones by assimilating 
space-borne microwave radiometer data and ground-based observations. Remote Sens. Environ., 101, 257-269.

Rodell, M., and P. R. Houser, 2004: Updating a land surface model with MODIS-derived snow cover. J. Hydrometeor., 5, 1064-1075.

Sturm, M., J. Holmgren, and G. E. Liston, 1995: A seasonal snow cover classification system for local to global applications. J. Climate, 8, 1261-1283.
Su, H., Z. L. Yang, G. Y. Niu, and R. E. Dickinson, 2008: Enhancing the estimation of continental-scale snow water equivalent by assimilating MODIS snow cover with the ensemble Kalman filter. J. Geophys. Res., 113, D08120, doi:10.1029/2007JD009232.

Zaitchik, B. F., and M. Rodell, 2009: Forward-looking assimilation of MODIS-derived snow-covered area into a land surface model. J. Hydrometeor., 10, 130-148. 